\title{
Mitochondria morphopathological changes in human congenital hydrocephalus, Arnold-Chiari malformation and postmeningitis hydrocephalus. An electron microscopic study
}

\begin{abstract}
Cerebral cortical biopsies of 16 patients with clinical diagnosis of congenital malformations, Arnold- Chiari malformation and postmeningitis hydrocephalus were studied to establish mitochondrial morphopathological alterations. Cortical biopsies obtained in the surgical room were immediately processed by conventional technique for transmission electron microscopy. Three injured mitochondrial morphological patterns were found: Swollen clear mitochondria, swollen dense mitochondria, and dark degenerated mitochondria were frequently observed in hydrocephalic parenchyma. Swollen clear mitochondria exhibited low electron dense matrix, enlarged intracristal space and continuity of outer and inner mitochondrial membranes. Swollen dense mitochondria showed high electron dense matrix and swollen fragmented cristae. Dense degenerated mitochondria displayed overall high electron density of matrix and mitochondrial membranes. Such injured mitochondrial pattern are mainly related with nerve cell death and considered markers of lethal nerve cell injury.
\end{abstract}

Keywords: mitochondria, congenital hydrocephalus, hydrocephalic edema, electron microscopy
Volume 8 Issue 2 - 2018

\section{Orlando J Castejón}

Biological Research Institute "Dres, Universidad del Zulia and Clinical Neuroscience Institute,Venezuela

Correspondence: Orlando J Castejón, Instituto de Investigaciones Biológicas, Facultad de Medicina, Universidad del Zulia,Apartado 526, Maracaibo 4003-A,Venezuela, Email ocastejo@gmail.com

Received: January 31, 2018 | Published: March 22, 2018

\section{Introduction}

Vuia ${ }^{1}$ reported two twin brothers diagnosed with congenital spongy degeneration of the brain featured by accumulation of lamellar bodies within the mitochondria, and free in the cellular cytoplasm with tendency to form inclusions of the multilamellar or finger-print type. Watanabe ${ }^{2}$ described in a 51/2-year-old boy with congenital myopathy associated with communicating hydrocephalus myofibrillar disorganization and Z-band streaming with decrease or absence of mitochondria. These Authors considered that common pathogenetic mechanism may have been involved in the development of both the myopathy and the hydrocephalus. Kaur and Ling $^{3}$ found swelling and disintegration of mitochondria in ricin-induced hydrocephalus in postnatal rats. Madhavi and $\mathrm{Jacob}^{4}$ carried out a morphometry study of mitochondria in the choroidal ependyma of hydrocephalic guinea pigs, and observed that the inner membrane of the mitochondria including cristae exhibited a significant decrease in the hydrocephalic animals. According to these Authors, this reduction in the surface area could probably be attributed to the reduced activity of choroid ependymal cells in obstructive hydrocephalus. Castejón ${ }^{5}$ distinguished variable degrees of mitochondrial swelling in human hydrocephalic cerebral cortex. Boillat et al. ${ }^{6}$ described distorted mitocondria in the deep cortical pyramidal cells of infant rats with inherited hydrocephalus. Castejón et al. ${ }^{7}$ examined in details the pathological changes of mitochondria in the edematous human cerebral cortex associated to severe and complicated brain trauma, tumors, and in a preliminary way the human hydrocephalus.

Castro-Gago et al. ${ }^{8}$ carried out an analysis of muscle biopsies and described light microscopic morphology and ultrastructural alterations typical of mitochondrial disorders, and low levels of complexes III and IV of the mitochondrial respiratory chain in congenital hydranencephalic-hydrocephalic syndrome. Morava et al. ${ }^{9}$ reported mitochondrial dysfunction in Brooks-Wisniewski-Brown syndrome with a significantly compromised of mitochondrial oxidative phosphorylation. These findings raised the possibility that at least some cases of congenital hydranencephalic-hydrocephalic syndrome may be due to alterations in the mitochondrial respiratory chain. Balaratnasingam et al. ${ }^{10}$ demonstrated mitochondrial cytochrome c oxidase expression in the central nervous system at elevated sites of pressure gradient elevation in hydrocephalus, and emphasized the importance of pressure gradients in regulating mitochondrial function in the central nervous system.

Fine structural changes of mitochondria in experimental cerebral edema have been widely reported since the advent of transmission electron microscopy. ${ }^{11-13}$ Ultrastructural pathology of neuronal mitochondria, after transient and permanent ischemia and anoxia in experimental animals, have reported that mitochondria undergo a sequence of profound alterations in structure and function, which appear to contribute to cell death. ${ }^{14-18}$

More recently, Baloyannis ${ }^{19}$ reported substantial morphological and morphometric changes of the mitochondria in the neurons of the hippocampus, the neocortex, the cerebellar cortex, the thalamus, the globus pallidus, the red nucleus, the locus coeruleus, and the cerebellar climbing fibers.

In the present study we systematically examine the mitochondrial alterations in hydrocephalic neurons, glial cells, and capillary wall. This study has been carry out using cortical biopsies of living hydrocephalic patients obtained at the surgical intervention, as a future step toward characterizing mitochondria as lethal markers of 
nerve cell death. To the best of our knowledge this approach has not been previously reported thus far.

\section{Material and methods}

Cortical biopsies of 16 neonate, infant and young patients, ranging from 10 days to 21 years-old, with clinical diagnosis of congenital hydrocephalus, Arnold-Chiari malformation, postmeningitis hydrocephalus and pinealome of third ventricle were examined with the transmission electron microscope. The Table No.1 contains the clinical data and lists the cortical regions from which the cortical biopsy was taken during neurosurgical treatment. The neurosurgical study was performed and the cortical biopsies were taken according to basic principles of Helsinki Declaration. Two to five $\mathrm{mm}$ thick cortical biopsies were immediately fixed in the surgical room in $4 \%$ glutaraldehyde- $0.1 \mathrm{M}$ phosphate or cacodylate buffer, $\mathrm{pH} 7.4$, at $4^{\circ} \mathrm{C}$. After 2 hours glutaralhehyde-fixation period, the cortical biopsies were divided into approximately $1 \mathrm{~mm}$ fragments and observed under a stereoscopic microscope to check the quality of fixation of the sample, glutaraldehyde diffusion rate and the brownish coloration of the surface and deeper cortical regions, indicative of good glutaralhehyde fixation by immersion technique. The cortical slabs were also performed to assure optimal diffusion rate of secondary osmium tetroxide fixatives. Immersion in fresh glutaraldehyde solution of $1 \mathrm{~mm}$ slices was done for 2 hours. Secondary fixation in $1 \%$ osmium tetroxide- $0.1 \mathrm{M}$ phosphate buffer, $\mathrm{pH} 7.4$, was carried out for 1 -2hours at $4^{\circ} \mathrm{C}$. Black staining of the cortical slices was also observed under a stereoscopic microscope to check osmium tetroxide diffusion rate and quality of secondary fixation. They were then rinsed for 5 to 10 minutes in phosphate or cacodylate buffer of similar composition to that used in the fixative solution, dehydrated in increasing concentrations of ethanol, and embedded in Araldite or Epon. For proper orientation during the electron microscope study and observation of cortical layers, approximately 0.1 to $1 \mu \mathrm{m}$ thick sections were stained with toluidine blue and examined with a Zeiss photomicroscope. Ultrathin sections, obtained with Porter-Blum and LKB ultramicrotomes were stained with uranyl acetate and lead citrate and observed in a JEOL 100B transmission electron microscope (TEM) at magnifications ranging from 30,000 to $60,000 \mathrm{X}$. For each case, approximately 50 electron micrographs were studied. The material and method has also been published elsewhere. ${ }^{5,7}$

\section{Results}

Swollen clear mitochondria were observed in non-pyramidal neurons in all cases under study characterized by swollen clear mitochondrial matrix (Figure 1) (Figure 2). The swollen dense mitochondria appeared as ovoid or enlarged profile organelles with edematous cristae (Figure 3). Both mitochondrial populations exhibited continuous inner and outer mitochondrial membranes, dilated intracristae space, and fragmentation or dissolution of mitochondrial cristae in severe brain edema. Some hydrocephalic neurons showed very long and dark mitochondria (Figure 4) surrounding the Golgi complex region (GC), and apparently associated with large Golgi vacuole. At the level of swollen and degenerated axosomatic presynaptic endings dark mitochondria were found coexisting with clear swollen mitochondria in the notably edematous postsynaptic neuron (Figure 5). In areas of severe hydrocephalic edema we found dark degenerated mitochondria (Figure 6). At the level of capillary wall, the swollen perivascular end-feet astrocytes exhibited dense mitochondria with dilated and fragmented cristae (Figure 7).

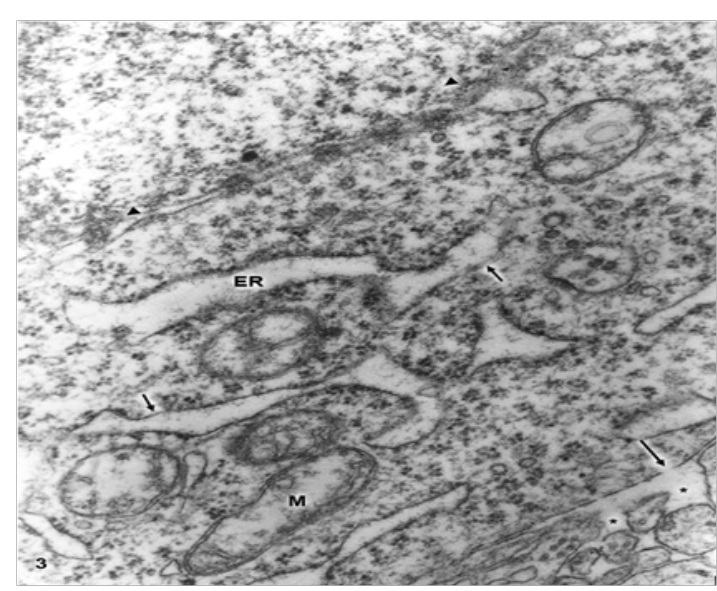

Figure I Congenital hydrocephalus. Right frontal cortex. Non-pyramidal neuron exhibiting swollen clear mitochondria (M), swollen fragmented plasma membrane (long arrow), distended endoplasmic reticulum cisterns (ER), detachment of membrane associated ribosomes (short arrows), and disassembly of some nuclear pores (arrowheads). Note the enlarged extracellular space in the neighboring neuropil (asterisks). X60.000.

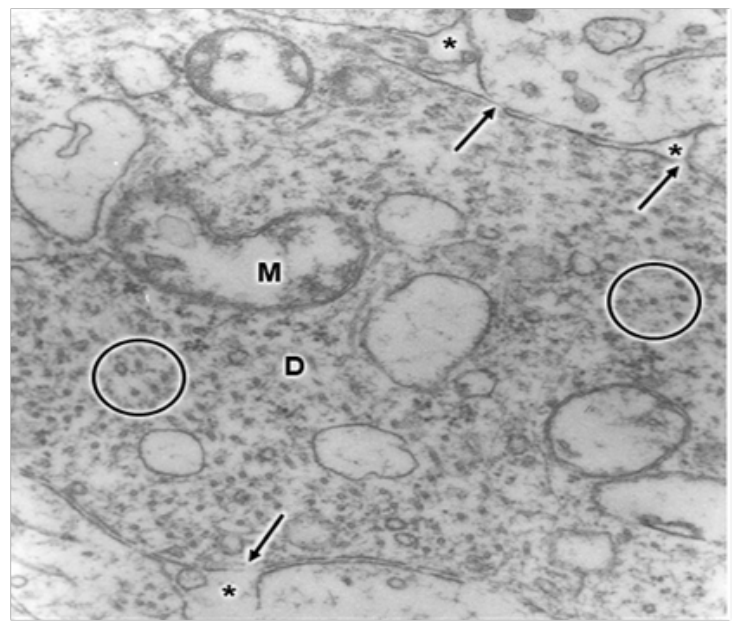

Figure 2 Congenital hydrocephalus associated with lumbar meningomielocele. Right parietal cortex. Neuropil of a 12 days-old neonate showing the longitudinal section of an edematous dendritic process (D) depicting swollen clear mitochondria with fragmented cristae and severe edematous mitochondrial matrix $(M)$.The circles indicate the cross sectioned microtubules and neurofilaments. The long arrows label the disrupted dendritic plasma membrane. Note the dilated extracellular space (asterisks) surrounding the dendritic profile that features hydrocephalus or interstitial brain edema. X45.000.

\section{Discussion}

In the present study we have found three different types of mitochondrial morphology in neurons, astrocyte cells, and at the capillary wall of patients with congenital malformations and peritumoral hydrocephalus. Solenski et al. ${ }^{19}$ reported dense cortical neuronal mitochondria exposed to severe ischemic-reperfusion conditions, whereas increasing loss of mitochondrial density with pronounced swelling were observed in permanent ischemia. The present study shows that swollen dense mitochondria appear more frequently at the level of parenchymal regions with sustained and permanent nerve cell ischemia. In addition, we have found in 
severe hydrocephalic edema enlargement of intracristal space and fragmentation of cristae. The above mentioned findings indicate that mitochondria show significantly different degrees of ischemic injury, expressed by the electron density changes of mitochondrial matrix. The matrix density is apparently related with aggregation of proteins responsible by its omiophilic property. The fragmentation of mitochondrial cristae suggest that oxidative phosphorylation of ADP, the precursors of high-energy phosphate bond of ATP, no longer occurs. In addition, suppose an interruption of mitochondrial membrane intracellular transport, which cause respiration-dependent extrusion of $\mathrm{H}^{+}$and accumulation of $\mathrm{Ca}^{2+}$ from the cytoplasm. ${ }^{20}$ During ischemia the lack of oxygen blocks oxidative metabolism so there is no energy to maintain the membrane potential required to drive $\mathrm{Ca}^{2+}$ uptake into the mitochondria. ${ }^{21}$ However, in brain edema mitochondria can accumulate excessive amounts of $\mathrm{Ca}^{2+}$ and become overloaded. ${ }^{22}$ When this occurs, mitochondria undergo a permeability transition of the inner mitochondrial membrane, ${ }^{22}$ release $\mathrm{Ca}^{2+}$, undergo swelling and become uncoupled, thereby losing the ability to produce ATP, and inducing nerve cell death. Therefore, neuronal death by necrosis or apoptosis depends of mitochondrial function. ${ }^{23}$ Presumably hydrocephalic or interstitial edema induces a high conductance of mitochondrial permeability transition pore or megachannel ${ }^{24}$ in the inner mitochondrial membrane, which causes mitochondrial swelling. In this context mitochondrial swelling should be considered as a epiphenomenon ${ }^{25}$ preceding nerve cell death.

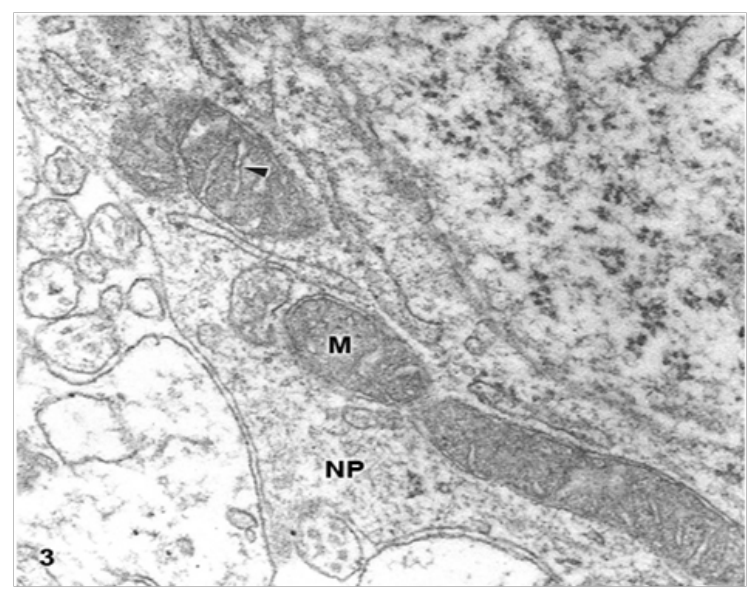

Figure 3 Congenital hydrocephalus.Arnold-Chiari malformation. Right frontal cortex. Non-pyramidal neuron (NP) showing swollen mitochondria (M) with a dark matrix and swollen, clear, and transversally oriented cristae (arrowhead) X60.000.

Mitochondria accumulate much of the post-ischemic calcium entering the neurons via the chronically activated N-methylD-aspartate receptors contributing to excitotoxicity. ${ }^{26}$ Calcium overload of nerve cell mitochondria plays a key role in excitotoxic and ischemic brain injury. According to Kristian et al., ${ }^{23}$ calcium induces large-amplitude swelling and matrix vacuolization. Calcium accumulation was earlier reported by Gutierrez Diaz et al. ${ }^{16}$ in nerve cell mitochondria, at the level of the synaptic vesicles, Golgi apparatus, lysosomes and glial and neuronal nuclei. In addition, mitochondria $\mathrm{Ca}^{2+}$ overload excessively activates phospholipases and other degradative enzymes leading to mitochondrial damage. ${ }^{7}$ Nitric oxide and its derivative peroxinitrite inhibit mitochondrial respiration (complexes I, II and V). NO-induced inhibition of respiration in brain nerve terminals result in rapid glutamate release, which might also contribute to neurotoxicity. Peroxinitrite causes opening of the mitochondrial permeability transition pore, resulting in release of cytochrome c, which might then trigger apoptosis. ${ }^{27}$

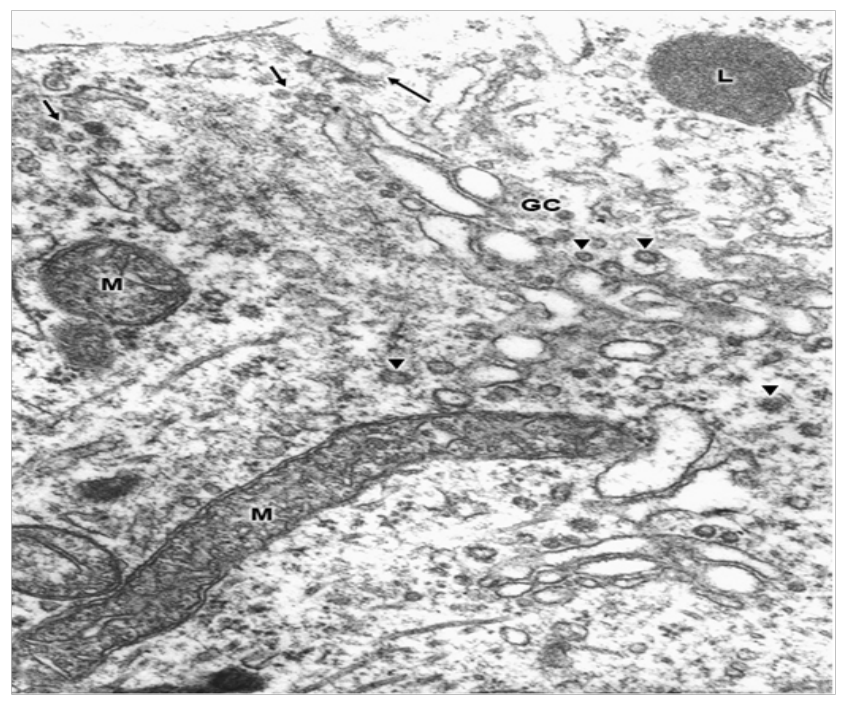

Figure 4 Congenital hydrocephalus. Elongated mitochondrion $(M)$ in the vicinity of Golgi complex (GC) in contact with a large Golgi vacuole. The arowheads point out the small Golgi vesicles.

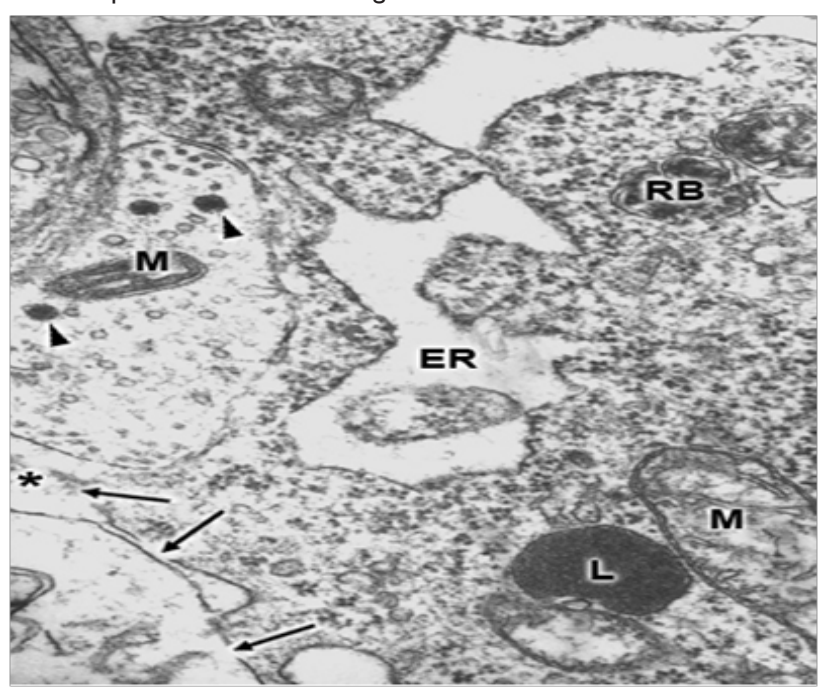

Figure 5 Congenital hydrocephalus. Right parietal cortex. Dark small dense mitochondria in an edematous and degenerated presynaptic axosomatic ending (M). The non-pyramidal neuron shows plasma membrane disruption (long arrows) and communication with the extracellular space (short arrow), lacunar enlargement of endoplasmic reticulum (ER. A lysosome (L) and residual bodies (RB) also are seen. $X 48.000$.

Mitochondrial electron transport also generates reactive oxygen intermediates (ROI). A large increase of ROI induce collapse of mitochondrial membrane potential and neuronal cell death The elevated intracellular $\mathrm{Ca}^{2+}$ and exposure to fatty acids, which alter the physical properties of mitochondrial membranes and inhibition of mitochondrial respiratory components, may enhance this leak of ROI from mitochondria. ${ }^{28,29}$ Lipid peroxidation occurs also in brain edema following ischemia and hypoxia ${ }^{30}$ which could be responsible for the mitochondrial membrane damage. 


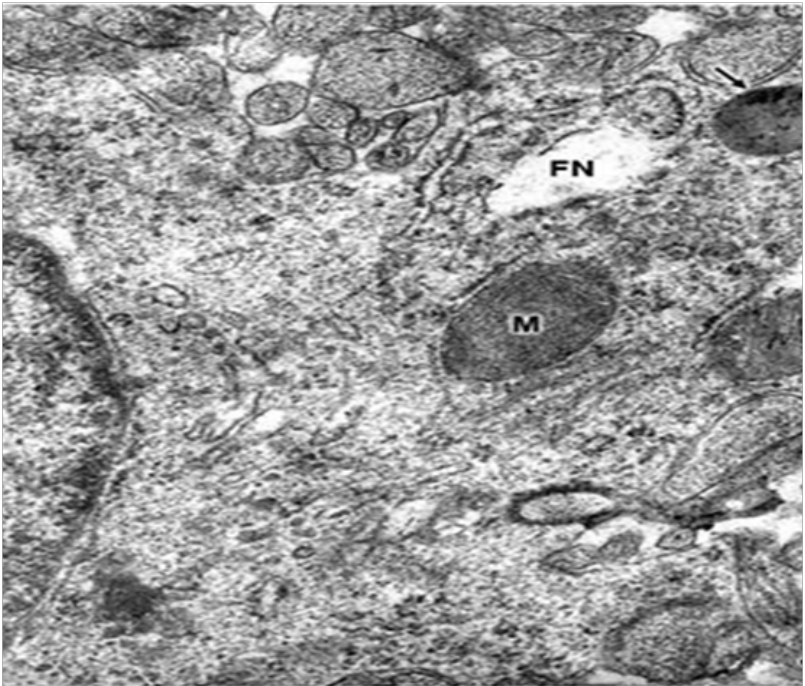

Figure 6 Congenital hydrocephalus and Arnold-Chiari malformation. Right parietal cortex. Severe hydrocephalic edema showing a non-pyramida neuron containing dense degenerated mitochondria $(\mathrm{M})$, and areas of focal cytoplasmic necrosis (FN).

Clinical applications and research on the role of mitochondria in the genesis of human bydrocephalic edema.

According to the neurosurgical study (Table 1), the patients exhibited neurologic symptoms and sequelae, primarily related with the impaired mitochondrial respiration. Impairment of cerebral energy metabolism would explain the functional deficits, neuropsychiatric Table I Neurosurgical study.

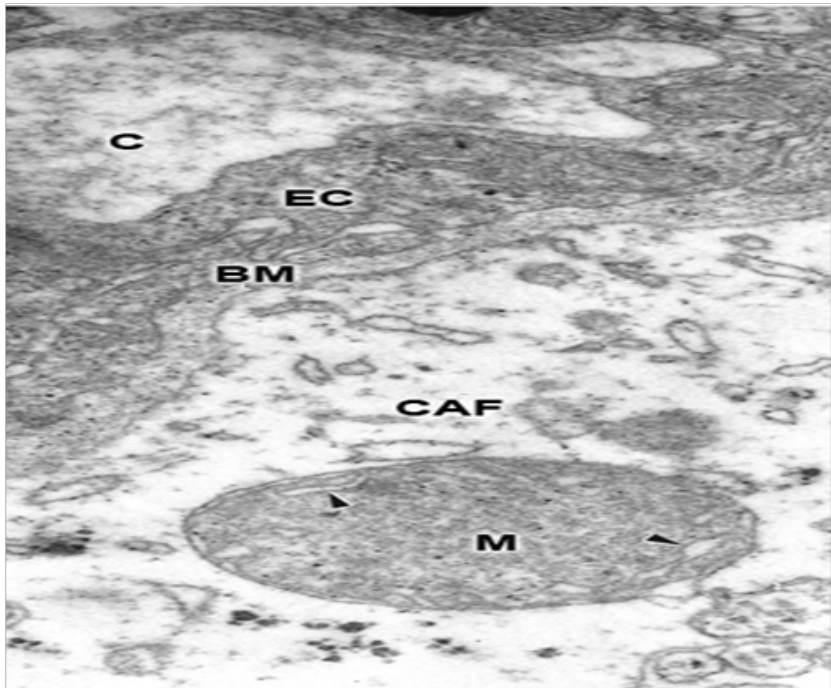

Figure 7 Comunicant hydrocephalus. Parietal cortex. Clear and edematous perivascular astrocytic astroctic end-foot (CAF) showing a dense mitochondrion (M) with clear swollen cristae (arrowheads) attached to the capillary basement membrane (BM).The peripheral endothelial cell cytoplasm (EC) and the capillary lumen (C) also are seen. X36.000.

sequelae, convulsions and disturbance in the state of consciousness in the patient under study. According to our study, mitochondria should be considered as important lethal marker organelle ${ }^{31}$ which undergo profound changes following ischemia and anoxia. This view is partially in agreement with Wagner et al. ${ }^{32}$ observations on delayed onset of neurologic deterioration in cats following ischemia/anoxia.

\begin{tabular}{|c|c|c|c|c|}
\hline $\begin{array}{l}\text { Sample } \\
\text { identification }\end{array}$ & $\begin{array}{l}\text { Age and } \\
\text { sex }\end{array}$ & Clinical data & Diagnosis & Biopsy region \\
\hline $\begin{array}{l}\text { I.HLCS } \\
\mathrm{H} \mathrm{I}\end{array}$ & Im, F & Increase of cephalic circumference. & $\begin{array}{l}\text { Uncompensatecommunicant } \\
\text { hydrocephalus. }\end{array}$ & Right parietal cortex \\
\hline $\begin{array}{l}\text { 2.EEAT } \\
\mathrm{H} 2\end{array}$ & Im, F & Increase of cephalic circumference. & $\begin{array}{l}\text { Uncompensate congenital } \\
\text { hydrocephalus. }\end{array}$ & $\begin{array}{l}\text { Right temporo-parietal } \\
\text { cortex. }\end{array}$ \\
\hline $\begin{array}{l}\text { 3LMBC } \\
\mathrm{H} 3\end{array}$ & $\mathrm{Im}, \mathrm{F}$ & $\begin{array}{l}\text { Increased cephalic circumference. } \\
\text { Hypertensive fontanelles. }\end{array}$ & Congenital communicant hydrocephalus. & Right frontal cortex. \\
\hline $\begin{array}{l}\text { 4. DEMI } \\
\mathrm{H} 4\end{array}$ & $6 \mathrm{~m}, \mathrm{M}$ & $\begin{array}{l}\text { Increased cephalic circumference. Left } \\
\text { peridural abscess. }\end{array}$ & Congenital hydrocephalus. & $\begin{array}{l}\text { Right temporo- parietal } \\
\text { cortex. }\end{array}$ \\
\hline 5.FJRA & IOd,M & $\begin{array}{l}\text { Bulding of fontanelles and increased } \\
\text { cephalic circumference after surgical } \\
\text { correction of lumbar meningomye-locele. }\end{array}$ & $\begin{array}{l}\text { Arnold-Chiari syndrome. Communicant } \\
\text { hydrocephalus }\end{array}$ & Frontal cortex. \\
\hline 6.CMV & $2 m, F$ & $\begin{array}{l}\text { Increased cranial volu-me, hypertensive } \\
\text { fon-tanelles, deviation of gaze to the } \\
\text { right, external rotations of both legs } \\
\text { and increased tendinous re-flexes after } \\
\text { treatment of meningomyelo-cele }\end{array}$ & $\begin{array}{l}\text { Arnold-Chiari malformation. } \\
\text { Hydrocephalus.Parieto-occipital } \\
\text { abscess. }\end{array}$ & Right parietal cortex. \\
\hline $\begin{array}{l}\text { 7.UN } \\
\mathrm{CCH} 23\end{array}$ & $12 d, F$ & $\begin{array}{l}\text { Increased cephalic circumference after } \\
\text { treat-ment of lumbar me-ningomyelocele. }\end{array}$ & Congenital hydrocephalus. Meningocele. & Right parietal cortex. \\
\hline 8.IATF & $3 m, M$ & Febril syndrome. Meningitis. & Postmeningitis hydrocephalus. & Right frontal cortex. \\
\hline 9.NSM & $8 m, F$ & $\begin{array}{l}\text { Increased cranial volume since three } \\
\text { months. }\end{array}$ & Communicant hydrocephalus. & Right parietal cortex. \\
\hline
\end{tabular}

Citation: Castejón OA. Mitochondria morphopathological changes in human congenital hydrocephalus, Arnold-Chiari malformation and postmeningitis hydrocephalus. An electron microscopic study.J Neurol Stroke. 2018;8(2):99-104. DOI: I0.15406/jnsk.2018.08.00289 
Table Continued

\begin{tabular}{|c|c|c|c|c|}
\hline $\begin{array}{l}\text { Sample } \\
\text { identification }\end{array}$ & $\begin{array}{l}\text { Age and } \\
\text { sex }\end{array}$ & Clinical data & Diagnosis & Biopsy region \\
\hline I0.GAAPG & $3 m, M$ & $\begin{array}{l}\text { Meningeal syndrome. Tonic-clonic } \\
\text { convulsions, increased cephalic } \\
\text { circumference. }\end{array}$ & Postmeningitis hydrocephalus. & Frontal cortex. \\
\hline II.RGG & $4 \mathrm{~m}, \mathrm{~F}$ & $\begin{array}{l}\text { Increased cephalic circumference, } \\
\text { hypertensive fontanelles. }\end{array}$ & Congenital hydrocephalus. & $\begin{array}{l}\text { Right frontal cerebral } \\
\text { cortex. }\end{array}$ \\
\hline I2.HR & $2 y, F$ & $\begin{array}{l}\text { Increased cranial volume since } 4 \text { months } \\
\text { of age. }\end{array}$ & Communicant hydrocephalus. & Right frontal cortex. \\
\hline I3.ISS & $7 \mathrm{~m}, \mathrm{M}$ & $\begin{array}{l}\text { Increased cranial volume. Diagnosis of } \\
\text { subarachnoid hemorrhage after axial } \\
\text { computer tomography. }\end{array}$ & Communicant hydrocephalus. & Right frontal cortex. \\
\hline 14.JM & $2 l y, M$ & $\begin{array}{l}\text { Sudden increase of cephalic circumference. } \\
\text { Tonic convulsions. }\end{array}$ & Pinealome of third ventricle. & Posterior parietal cortex. \\
\hline I5.CC & $10 y, M$ & Increased cranial volume. & Comunicant hydrocephalus. & Parietal cortex. \\
\hline I6.EV & $5 y, F$ & Increased cephalic circumference. & Comunicant hydrocephalus. & Parietal cerebral cortex. \\
\hline
\end{tabular}

The findings herein described suggest an early and urgent clinical and surgical intervention in child with congenital hydrocephalus in order to avoid mitochondrial damage, nerve cell death and to improve clinical outcome. The many processes involved in injury conditions, such like that cited above, such as free radical formation, intraneuronal calcium influx and calcium-mediated intracellular reactions, excitotoxicity by glutamate and possibly other neurotransmitters, glial oxygen changes, lipid peroxidation and programmed cell death or necrosis, should be considered in conducting a treatment protocol.

\section{Conclusion}

Three injured mitochondrial morphological patterns were found in hydrocephalic brain parenchyma: Swollen clear mitochondria, swollen dense mitochondria, and dark degenerated mitochondria. Swollen clear mitochondria exhibited low electron dense matrix, enlarged intracristal space and continuity of outer and inner mitochondrial membranes. Swollen dense mitochondria showed high electron dense matrix and swollen fragmented cristae. Dense degenerated mitochondria displayed overall high electron density of matrix and mitochondrial membranes. Such injured mitochondrial pattern are mainly related with nerve cell death and considered markers of lethal nerve cell injury.

\section{Conflict of interest}

No conflict of interest. This research received no specific grant from any funding agency in the public, commercial, or not-for profit sectors.

\section{Acknowledgements}

This study has been partially carried out through a subvention obtained from CONDES-LUZ, Castejón Foundation and San Rafael Home Clinic. Maracaibo. Venezuela.

\section{References}

1. Vuia O. Congenital spongy degeneration of the brain (van BogaertBertrand) associated with micrencephaly and ponto-cerebellar atrophy (contributions to the pathology of glial dystrophy of intrauterin origin) Neuropadiatrie. 1997;8(1):73-87.
2. Watanabe K, Kumagai T, Wakayama Y, et al. Congenital myopathy and communicating hydrocephalus--a possible pathogenetic combination. Brain Dev. 1982;4(6):455-462.

3. Kaur C, Ling EA. Induced hydrocephalus in postnatal rats following an intracerebral injection of ricin. J Hirnforsch. 1993;34(4):493-501.

4. Madhavi C, Jacob M. Morphometry of mitochondria in the choroidal ependyma of hydrocephalic guinea pigs. Indian J Med Res. 1992;96:7277.

5. Castejón OJ. Transmission electron microscope study of human hydrocephalic cerebral cortex. J Submicrosc Cytol Pathol. 1994;26(1):29-39.

6. Boillat CA, Jones HC, Kaiser GL, et al. Ultrastructural changes in the deep cortical pyramidal cells of infant rats with inherited hydrocephalus and the effect of shunt treatment. Exp Neurol. 1997;147(2):377-388.

7. Castejón OJ, Castejón HV. Structural patterns of injured mitochondria in human oedematous cerebral cortex. Brain Injuri. 2004;18(11):11071126.

8. Castro-Gago M, Alonso A, Pintos-Martínez E, et al. Congenital hydranencephalic-hydrocephalic syndrome associated with mitochondrial dysfunction. J Child Neurol. 2011;14(2):131-135.

9. Morava E, Rodenburg R, HolF, etal. Mitochondrial dysfunction in BrooksWisniewski-Brown syndrome. Am J Med Genet. 2006;140(7):752-756.

10. Balaratnasingam C, Pham D, Morgan WH, et al. Mitochondrial cytochrome $\mathrm{c}$ oxidase expression in the central nervous system is elevated at sites of pressure gradient elevation but not absolute pressure increase. J Neurosci Res. 2009;87(13):2973-2982.

11. Koizumi J, Shiraishi H. Fine structural changes of mitochondria in cerebral edema and dehydration. Arch Histol Jap. 1970;32(3):241-249.

12. Brown AW, Brierley JB. The earliest alteration in rat neurons and astrocytes after anoxia-ischemia. Acta Neuropathol. 1973;23(1):9-22.

13. Clendenon NR, Allen N. Organelle and membrane defects: Lysosomes, mitochondria, and cell membrane. In: AJ Popp, RS Bourke, et al. editors. Seminars in Neurological Surgery. Raven Press; 1979. p. 115-129.

14. Hossmann KA, Grosse Ophoff B, Schmidt-Kastner R. et al. Mitochondrial calcium sequestration in cortical and hippocampal neurons after prolonged ischemia of the cat brain. Acta Neurophatol. $1985 ; 68(3): 230-238$ 
15. Ikreny K, Dora E, Hajos F, et al. Metabolic and electron microscopic studies post mortem in brain mitochondria. Adv Exper Med Biol. 1976;75:159-164.

16. Gutierrez-Diaz JA, Cuevas P, Reimers D, et al. Quantitative electron microscopic study of calcium accumulation in cerebral ischemia mitochondria. Surg Neurol. 1985;24(1):67-72.

17. Dzhafarov AI, Magomedov NM, Babaev KhF, et al. Lipid peroxidation in the synaptosomal and mitochondrial fraction of separate brain structures in hypoxia. Biulleten'Eksper Biol Med. 1989;107(3):305-307.

18. Baloyannis SJ. Mitochondria are related to synaptic pathology in Alzheimer's disease. Int J Alzheimers Dis. 2011;10:305-395.

19. Solenski JJ, diPierro CG, Trimmer PA, et al. Ultrastructural changes of neuronal mitochondria after transient and permanent cerebral ischemia. Stroke. 2002;33(3):816-824.

20. Anderson MF, Sims NR. Mitochondrial respiratory function and cell death in focal cerebral ischemia. J Neurochem. 1999;73(3):1189-1199.

21. Gnaiger, E, Kuznetsov, AV, Reiger G, et al. Mitochondrial defects by intracellular calcium overload versus endothelial cold ischemia/ reperfusion injury. Transplant Internat. 2000;(13 Suppl 1):S555-557

22. Morley P, Tauskela JS, Hakim AM. Calcium overload. In: Walz W, editor. Cerebral Ischemia. Molecular and Cellular Pathophysiology. Humana Press; 1999. p. 69-104.

23. Kristian T, Watherby T.M, Bates TE, et al. Heterogeneity of the calcium-induced permeability transition in isolated non-synaptic brain mitochondria. J Neurochem. 2002;83(6):1297-1308.
24. Dubinsky JM, Brustovetshky N, Pinelis V, et al. The mitochondrial permeability transition: the brain's point of view. Biochemical Society Symposium. 1999;66:75-84.

25. Rosenthal M, Mumford P, Sick TJ, et al. Mitochondrial hyperoxidaton after cerebral anoxia/ischemia. Epiphenomenon or precursor to residual damage? Adv Exper Med Biol. 1997;428:189-195.

26. Nicholls DG, Budd S, Ward MW, et al. Excitotoxicity and mitochondria Biochemical Society Symposium. 1999;66:55-67.

27. Brown GC, Borutaite V. Nitric oxide, cytochrome c and mitochondria Biochemical Society Symposium. 1999;66:17-25.

28. Du G, Mouithys-Michalad A, Sluse FE. Generation of superoxide anion by mitochondria and impairment of their functions during anoxia and reoxygeneration in vitro. Free Radical Biol Med. 1998;25(9):1066-1074.

29. Perez Pinzon MA, $\mathrm{Zu}$ GP, Born J. Cytochrome $\mathrm{C}$ is released from mitochondria into the cytosol after cerebral anoxia or ischemia. $J$ Cerebral Blood Flow Metab.1999;19(1):39-43.

30. Ginsberg MD, Watson BD, Bustos R. Peroxidative damage to cell membrane following cerebral ischemia. A cause of ischemic brain injury. Neurochem Pathol. 1988;9:171-193.

31. Castejón OJ. The thesis of mitochondria as marker of lethal injury in the traumatic human brain edema. An electron microscopic study using cortical biopsies. Acta Microscópica. 2008;17:16-27.

32. Wagner KR, Kleinholz M, Myers RE. Delayed decreases in specific brain mitochondrial electron transfer complex activities and cytochrome concentration following anoxia/ischemia. J Neurol Sci. 1990;100(12):142-151. 